\title{
Strategies to develop and promote public-private partnerships (PPPs) in the provision of hospital services in Iran: a qualitative study
}

\author{
Ahmad Sadeghi ${ }^{1}$, Omid Barati ${ }^{2}$, Peivand Bastani ${ }^{2}$, Davood Daneshjafari ${ }^{3}$, Masoud Etemadian ${ }^{4}$
}

${ }^{1}$ Ph.D. Candidate of Health Services Management, Department of Health Services Management, School of Management and Medical Informatics, Shiraz University of Medical Sciences, Shiraz, Iran

${ }^{2}$ Ph.D. of Health Services Management, Assistant Professor, Health Human Resources Research Center, School of Management and Medical Informatics, Shiraz University of Medical Sciences, Shiraz, Iran

${ }^{3} \mathrm{Ph}$.D. of Economics, Assistant Professor, Department of Economics, Allameh Tabatabai University, Tehran, Iran

${ }^{4}$ Urologist, Associate Professor, Department of Urology, Hasheminejad Kidney Center, Iran University of Medical Sciences, Tehran, Iran

\section{Type of article: Original}

\begin{abstract}
Introduction: Public-Private Partnerships (PPPs) have been constructively considered in recent years to reform health sectors in many countries. This study aimed at explaining the strategies to develop and promote PPPs in the provision of hospital services in Iran.

Methods: This qualitative study was conducted in 2015. The study population consisted of experts and professionals of the health system and individuals familiar with PPPs and roles in the development of such models in hospital services in Iran that were selected through purposeful sampling, and semi-structured interviews were used for data collection. To this end, 18 experts and professionals of the health system and individuals familiar with PPPs and roles in the development of such models in hospital services in Iran were selected. The data were analyzed and classified using MAXQDA10 software and content analysis, respectively.

Results: According to the results of this study, four main themes and 20 subthemes in terms of strategies to develop and promote PPPs in the provision of hospital services in Iran were identified, including changes in policies and laws, socio-cultural changes, improvement of mechanisms and current processes, and financial and capital capacity building.

Conclusion: To develop and promote PPPs in the provision of hospital services, there is a need to consider prerequisites and measures to help such partnerships to be effective and produce valuable results.

Keywords: Public-Private Partnership (PPP), hospital services, qualitative study
\end{abstract}

\section{Introduction}

Hospitals, as the most important healthcare organizations, have a leading role in health promotion in society, and their coordinated action with a set of political, social, and cultural factors leads to people's health. Since this sector is the main consumer of a large part of the healthcare budget in a country, full attention to its performance and costs is of particular importance. Annually, immense sums of money are expended on buildings, maintenance, and reconstruction of hospitals around the world, but evidence is rare regarding achievement of the expected benefits from such spending. In 1989, the World Health Organization (WHO) estimated that about $40 \%$ of the resources available to the health sector in the U.S. were wasted, and it showed that the resources that can be saved by increased efficiency were very appreciable (1). Financing by the public sector cannot be responsive to the everincreasing expenses in the health system. Obligations to finance by public sector as well as increasing costs have created the need for public-sector hospitals to reduce their expenses (2). These factors have led governments pursuing various approaches to deal with these problems as well as ways to curb costs, raise capital, and ultimately

\section{Corresponding author:}

Assistant Professor Dr. Omid Barati, Health Human Resources Research Center, School of Management and Medical Informatics, Shiraz University of Medical Sciences, Shiraz, Iran.

Tel: +98.7132340774, Fax:+98.7132340039, Email: omidbarati40@gmail.com

Received: January 07, 2016, Accepted: March 05, 2016, Published: April 2016

iThenticate screening: March 06, 2016, English editing: April 01, 2016, Quality control: April 08, 2016

(C) 2016 The Authors. This is an open access article under the terms of the Creative Commons Attribution-NonCommercialNoDerivs License, which permits use and distribution in any medium, provided the original work is properly cited, the use is non-commercial and no modifications or adaptations are made. 
achieve better health outcomes through more active participation of the private sector in providing services and also financing this sector (3). To benefit from the capabilities of public and private sectors in the form of a hybrid model, the Public-Private Partnership (PPP) model was introduced in 1990, and it has been used constructively in recent years to reform healthcare sectors in many countries. In fact, PPP can be a powerful political tool for improving and promoting the survival and quality of services in public hospitals (4). PPP is trying to implement some of the principles of the private sector, including economic balance and revenues through a rigorous financial management to solve some major problems in the public sector (5). Several definitions of PPP have been presented by different sources. One of the fairly comprehensive definitions is as follows: contractual agreement between public sector and private sector in which the private sector executes some government activities on behalf of the private sector within a specified time, in a framework of negotiations, with a risk-adjusted extent, and determined executive rewards. Each of these sectors gains considerable benefits and interests. In fact, PPP includes a range of traditional methods of procurement of services by the public sector and full privatization (6). There is a growing belief that partnership between public and private sectors can lead to increased efficiency, equality, accountability, quality, and accessibility in the health system. In PPP, the sectors can make use of mutually competitive advantages of each other in the fields of technology, knowledge, resources, skills, and management capabilities (7). Examination of different experiences of various countries on the use of different options of PPP indicates the impact of these options on the cost of providing services, amount of operation, access of the population covered, and other performance indicators of public hospitals (8). The results of several studies have suggested that several factors have been identified for the implementation and success of executing PPP projects. For example, some researchers have considered various factors to be important factors and requirements in the implementation of PPP (9-11). These factors include proper understanding of the project, stable economic and political conditions, adequate economic justification, sufficient initial capital, strong governance and management, appropriate allocation of risks, enough experience, use of reputable and competent contractors, and innovation in funding. Therefore, in order to achieve success in the implementation of PPP and its development and promotion, these factors should be considered to avoid any failure in the implementation and operation of these PPP projects. In Iran, more than half of the funds of the health sector are allotted to hospitals; however, the low hospital bed occupancy rate compared with that of developed countries reflects the fact that the available resources are not exploited properly, and it would necessitate the use of appropriate management methods. Therefore, policy-makers and senior officials are seeking ways to get out of this situation and implement appropriate policies and measures to improve the situation of hospitals in the country, especially in the public sector. Taking advantage of the potential capacity of the private sector in the hospital system is one of these policies (12). Considering the obligations in upstream documents, such as the overall policies of Article 44 of the Constitution of the Islamic Republic of Iran, on better and more interactions with the private sector (Provision 136), and given that the foundations of this model have been defined in the budget laws in 2015 and in the laws of the Fifth Socio-Economic Plan, it seems necessary to conduct a study to identify strategies to develop and promote PPPs in the provision of hospital services in Iran in order to raise awareness among policymakers and managers in the field of health planning and decision-making. It seems that implementing and promoting the PPP model can help develop some areas of health services, as it has done in different fields of the economy earlier (13). Overall, we can conclude that a managed PPP can even aid seemingly unlikely aspects of the public health sector, such as education and personnel management very much and help public hospitals overcome many of their age-long shortcomings and more recent constraints.

\section{Material and Methods}

This was an exploratory qualitative research study that sued content analysis and was conducted for a specific purpose in 2015. The statistical population consisted of experts and professionals of the health system and individuals familiar with PPP models and roles in the development of the model in hospital services in Iran. The purposive sampling method was used to conduct the interviews. This method is one of the most common methods of sampling in qualitative studies in which the group of participants is selected based on pre-specified criteria related to specific research questions (14). In this approach, participants are handpicked by the researcher because they have the features or the phenomena considered or they have rich information about specific cases (15). Likewise, in order to increase the diversity of attitudes, the purposive sampling method with maximum diversity was used in such a way that, after the first sample selection, the sample was asked to introduce other experts (16). The criterion for sample size in this study was similar to qualitative studies in terms of reaching the saturation level of data, and, when new codes were not obtained, the sampling was finished. Accordingly, 18 professionals and experts in Iran's health system were interviewed. Of these individuals, nine representatives of the public sector (Ministry of Health, University of Medical Sciences, and public hospitals) and nine representatives of the private sector (Moheb Institution, Moheb Hospital) were enrolled in the study. At first, the interview guide was prepared according to the 
theoretical background of the study and review of the related literature in a semi-structured form with seven questions. In order to determine the validity and reliability of the significance of the questions from the participants' perspectives, three pilot interviews were conducted with individuals who were not among the selected participants; according to their attitudes and in necessity, the required amendments were made to remove the defects. Ultimately, 10 final questions were decided upon to conduct the main interviews of this study. The interviews were administered in the form of individual, semi-structured interviews. Accordingly, first, general questions were asked to start the interviews; then, the process of interviews was directed based on the participant's answers to questions. Interviews were conducted by appointment, and the locations of the interviews were chosen by the participants. Thus, after coordination, all interviews were conducted in the participants' workplaces, and the duration of each interview ranged from 30 to 90 minutes, depending on the conditions and the willingness of the participants. All interviews were recorded, and, immediately after the end of each session, they were written down with the consent of the participants to determine the data saturation time and increase the accuracy and preciseness of transcribing the texts. In order to consider the ethical issues of this study, the informed consent of the participants was obtained, and they were assured that their participation and recording the interviews were voluntary. They also were assured that their information would remain confidential, available only to the researcher, and that they had the right to withdraw at any stage of the study. The content analysis method was used to analyze the data at each stage. This method is a specialized technique for processing scientific data, and it is used to determine the presence of certain words and concepts in the text to summarize, describe, and interpret the data $(17,18)$. To this end, the interviewer transcribed the contents after each interview. The transcriptions of the interviews were studied several times to obtain a general understanding of them. In addition, the transcribed texts for each interview were given to the relevant interviewees so they could provide comments or revisions. The interview texts were fed into MAXQDA software, version 10, and the initial codes were extracted. Then, with the cooperation and the use of the opinions of the participants and the members of the research team, the final codes and themes of the study were extracted. To consolidate the results, different strategies were used, such as member checks, submission of the transcribed and interpreted texts to the participants, and reception of their comments and suggestions, peer checks, and peer debriefing (19). Approval of the transcribed texts and the extracted codes and themes was conducted by two members of the research team with no conflict of interest regarding the subject of the study.

\section{Results}

Of the 18 interviewees present, all were male with the average age and working experience of $48 \pm 8.94$ and $23 \pm$ 7.81 years, respectively. According to the results of the study, four main themes and 20 sub-themes related to the strategies to develop and promote PPP in the provision of hospital services in Iran were identified, and they are provided in Table 1.

Table 1. Main themes and sub-themes of the strategies to develop and promote PPP in the provision of hospital services in Iran

\begin{tabular}{|l|l|}
\hline Themes & Sub-Themes \\
\hline $\begin{array}{l}\text { Changes in } \\
\text { Policies and Laws }\end{array}$ & $\begin{array}{l}\text { Stability in government policies, Improvement and enhancement of insurance and } \\
\text { associated insurance organizations, Competitive pricing, Balance between price and } \\
\text { quality in healthcare sector, Movement to the formation of board of trustees in hospitals, } \\
\text { acceptance the role of trustee and policy-maker by Ministry of Health and avoiding the } \\
\text { implementation role, Reform and actualization of tariffs }\end{array}$ \\
\hline $\begin{array}{l}\text { Socio-Cultural } \\
\text { Changes }\end{array}$ & $\begin{array}{l}\text { Changes in culture and public opinion and attraction of people's trust, National } \\
\text { commitment and coordination between government and parliament, Mental and attitudinal } \\
\text { paradigm shift of government towards private sector, Full support of partnership with } \\
\text { private sector by senior management and decision-makers of health sector }\end{array}$ \\
\hline $\begin{array}{l}\text { Improvement of } \\
\text { Current }\end{array}$ & $\begin{array}{l}\text { Creation of a strong and unified entity to manage the relationships with private sector, } \\
\text { Identification of a trustee and main executor of these types of partnerships, Transparency } \\
\text { Processes }\end{array}$ \\
$\begin{array}{l}\text { and proper management of existing patterns and their implementation, Development of a } \\
\text { fair and transparent contract in accordance with the project, Execution in a pilot form and } \\
\text { provision of infrastructure before implementation, Reduction in the size of government } \\
\text { bodies (decrease in chairmanship) }\end{array}$ \\
\hline $\begin{array}{l}\text { Financial and } \\
\text { Capital Capacity } \\
\text { Building }\end{array}$ & $\begin{array}{l}\text { Establishment of conditions and contexts to attract investors, Incentives for investors to } \\
\text { enter the field, Government guarantees to buy the service and also return on base and } \\
\text { benefit of investors }\end{array}$ \\
\hline
\end{tabular}




\subsection{Changes in Policies and Laws}

One of the factors that can provide the context for the development and promotion of PPP in the provision of medical services in Iran is changes in current policies and laws. In this regard, stable government policies could provide for the development of PPP. This is the issue that many interviewees highlighted. "Governments must have stable policies. On the economic issues, they cannot say everything as they like, [for instance] a President might come and say that I will reduce the bank interest to $5 \%$, one might come and abandon it; then, another one might come and say that I will reduce the bank interest to zero. This approach makes investors have no trust." (P5). Reform and restructuring of insurance in Iran was one of the other issues that, according to many interviewees, needed attention for the development of PPP. In this regard, one of the participants stated that: "We must have strong insurance organizations, those that can sign numerous contracts. Now, we have just one contract. It can cover a limited part of the services [as a result] insurance is not perfect. In some situations, people need more than that and it should have a better coverage of insurance." (P11). Some participants believed that the Ministry of Health should only have the task of trusteeship and policy-making and that it should not be involved in executive affairs. "The Ministry of Health is required to do as a trustee, as a supervisor, as a policy-maker and legislator. The private sector or PPPs, charities, and other organizations come and provide services. The Ministry of Health should only supervise and have the role of a trustee and policy-maker." (P8, P12). Some of the interviewees considered the formation of a Board of Trustees in hospitals as a starting point for the development of PPP and, consequently, chain hospitals. In this regard, one of the senior managers of the health system stated that: "Formation of chain hospitals needs that a hospital becomes an independent economic unit called the board of trustees. After that, this independent economic unit can invest to establish other branches in other provinces and even it is likely to do it with an external or internal partner." (P17).

\subsection{Socio-Cultural Changes}

Another issue that was identified to develop and promote PPP in Iran's hospitals was socio-cultural changes. Change in the mindset and belief of individuals regarding the use of the capacities of the private sector is one of the important things noted by the participants. They believed that the development and promotion of PPP requires changes in mentality and culture. "In my opinion, most of the problems are related to cultural ones; I mean the cultural mindset that is prevailing in the parliament, in government, in the Ministry of Health is in a way that they need no help, but when you analyze it; you find that the need is very serious and you should help them as soon as possible. If the cultural mindset shifts and they feel that they should make use of the capacities of the private sector, I think they could provide the background for PPP." (P2, P6). In this regard, one of the interviewees believed that: "In the healthcare sector, we should consider the issue of utilitarian in the private sector. We think people involved in the government are very good and all people in the private sector are bad. First of all, this mental paradigm must be changed." (P5).

\subsection{Improvements in Current Mechanisms and Processes}

Improvement in current mechanisms and processes is another important issue necessary to develop and promote PPP. One of these mechanisms highlighted by the majority of interviewees was creating a strong and single entity for managing relationships with private sector. "There should be a committee to issue the qualifications of private partners. In all countries, there is a very strong consortium that sets up the contracts, approves the qualifications of private sector, and monitors everything. We need such a framework which is supported and does not change with any changes in the government." (P14). Clarification of existing patterns and their management were among the important issues taken into account by many participants for the development and promotion of PPP in Iran. In this regard, one of the interviewees said that: "If PPP wants to promote, the example cases that have already started need at first a good management to have a good outcome. Now, our status and the activities we started (Moheb Institution) lead the non-governmental organizations have no tendency to this issue due to the problems that we were involved in. They say that you got into this work, did your best, got forward, and got involved in all the problems and challenges; so why the private sector should start the same thing. The government should start, come forward, and help and facilitate everything and ask the private sector to get forward." (P7). "Transparency is a very important issue. We have to clarify this model to help the private sector to step up. If these problems are not solved in this model, it cannot be expanded. We have to start from pilot cases. Because it helps us do it better and create a good motivation for the rest of private investors." (P17). Another strategy suggested to develop and promote PPP was the formulation of proper and understandable contracts. "My suggestion is to have someone outside of the health system in Iran, perhaps I should say an international consultant who studies our laws and then develops a strong legal agreement based on the laws in Iran in order to assure the investors that their capital is provided. The government is 
also confident that its rights are met according to the contract, and the investor and the government start to debate. We have problems with the agreements which are irrational and ambiguous." (P2).

\subsection{Financial and Capital Capacity Building}

Providing conditions and the background for attracting investment is another strategy that was mentioned by some individuals. In this respect, one of the participants believed that: "To make such partnerships happen in Iran, we need to do something that would help the investor prefer to invest in hospitals rather than in other places. There must be government guarantees for return on capital and earnings to the investor because no one tends to invest somewhere without any return on investment." (P13). One of the things that sets the stage for attracting investment in the health sector is considering incentives and motives awarded by the government. "The most important thing in the economy of health is individuals' participation in providing services through investment. To attract investors in the provision of healthcare services, we need to define different incentives from the government. The government has a number of facilities which can be given to the private sector to keep the total cost low; in other words, to increase the earnings. For example, the government can delete the price of land from this equation." (P4). Government guarantees for investors were one of the other issues that was highlighted by participants in order to develop and promote PPP. For example, one of the participants believed that: "The government needs to think ahead to develop its services and to play a prominent role in this regard. For example, the government needs to ensure that there is a market, there is a guarantee about the existing risks, and take these risks from the investors such as domestic risks and exchange rate risks." (P10).

\section{Discussion}

Most of the individuals who believed in the provision of healthcare services by a centralized public system in the past have argued that the private sector is an indispensable part of a national program of providing healthcare services and that the use of various methods of private-sector partnership can effectively contribute to improved quality, reduced costs, and better management of resources and efficiency (20). There should be prerequisites and arrangements for the development of these partnerships so that they can be effective and bring valuable results and outcomes. Four main strategies that were identified as the main factors in the development and promotion of PPPs in the provision of hospital services in Iran were changes in policies and laws, socio-cultural changes, improvement of current mechanisms and processes, and capital and financial capacity building. In terms of political and legal strategies, different countries have taken various measures in order to implement, develop, and promote PPP. For example, a separate chapter on PPP was considered in the Constitution in Thailand. In the UK, as one of the pioneers in PPP, units of PPP were established at the level of Ministries, and incentives to the private sector were recommended. In Germany, policies to support small firms to join PPPs were adopted (21). Although partnership with the private sector and the use of its capacities in Iran's 20-Year Prospective Plan and the provisions of the Fourth and the Fifth Development Plans were considered, the development and promotion of such partnerships in the healthcare sector require changes and amendments to existing laws and policies. It is better to approve legal provisions and regulations to strengthen PPP contracts by the government and the judicial system. In this regard, Grimsy and Lewis concluded that conflicts are inevitable in PPP without an efficient and optimal legal framework, and they stated that revisions in existing laws and policies must be taken into account for PPP projects to succeed (22).

Another strategy identified to develop and promote PPP in the provision of hospital services in Iran was sociocultural changes. In a study conducted in Sri Lanka, various strategies, such as changes in the mindset of health workforce, provision of education to the political leaders in the country, and culture-building in terms of accepting PPP in order to provide health services, were suggested for the development of PPP in the healthcare industry (23), which partially confirmed the results in our study. Government support is vital in the early years of the development of PPP projects or in a new market. Without adequate support by the government, the private sector will not be willing to get involved in PPP.

Improvement of current mechanisms and processes was one of the other strategies that was suggested for the development and promotion of PPP. In this respect, the results of a systematic study revealed the effectiveness of PPP projects on several factors, including writing a contract, role of partners, legal framework, and stakeholders' partnership (24). India also implemented PPP for some projects in a pilot form. In fact, the temporary and pilot implementation of the program has advantages that examine the feasibility of the program and can identify the strengths and weaknesses for the implementation of future programs (25). The PPP models of Hasheminejad Hospital and Moheb Institution in Iran were relatively successful examples among public hospitals, which provided 
capital entry into the health sector and could be promoted and expanded according to the existing laws and capacities. The experiences in other countries may not be exactly applicable in Iran, but it seems that the localization of this model and its adaptation with the conditions of the country could well change the administration of educational medical centers in Iran.

Financial and capital capacity building was considered as one of the other important factors for the development of PPP in hospital services in Iran. In fact, governments should provide the groundwork for attracting investment in health sector. To do so, incentives and motives for the entry of investors in this area should be taken into account. Such incentives and motives for private investors can provide an appropriate context for investment in the health sector. Stimuli and incentives, such as loans with reasonable interest rates and guarantees for reasonable returns on earnings, can be used in the regard. If governments provide these for the private sector, investors will be more motivated to finance in underprivileged areas, and this leads to a reduction in the financial burden on the governments to provide public services (26). In this regard, evidence suggests that the allocation of low-interest loans for PPP projects in Thailand, providing loans and facilities from the Development Fund in India, and allocation of funds and loans from the banks to the private partners in the UK have been some of the strategies and incentives for PPP development in the health sector (21). In the unique experience of PPP in Iran's health sector (Moheb Hospital), bank facilities were awarded to the private sector partner as an incentive to join the PPP projects; therefore, this kind of facilities and other financial incentives should continue for further development of PPP projects and motivate investors and the government to take steps to buy back the services from the private sector, consider reasonable profits for investors, and create confidence among them.

\section{Limitations}

This study encountered several limitations as follows: first, triangulation could not occur because the limited number of participants did not allow the researchers to use a mix-method design. Also, sequential interviews with one participant were not possible.

\section{Conclusions}

Identification of the factors that affect the development and promotion of PPP models before their implementation and execution can be very effective. In this study, various factors, such as changes in policies and laws, sociocultural changes, correction of current mechanisms and processes, and financial and capital capacity building, were identified as the most effective strategies in developing and promoting PPP in the provision of hospital services in Iran. Accordingly, given that this study was conducted using the content analysis method by means of interviews to collect the data, it is recommended that more precise investigations and case studies be conducted to extract and explore the influential components, the implementation process, and the achievements. Furthermore, given that the present results and their comparison with other international findings showed the importance of moving towards the implementation of PPP, it was recommended that appropriate studies be conducted before implementing this model in qualified hospitals in Iran.

\section{Acknowledgments:}

This article is part of a Ph.D. thesis in the field of health care management, and it was approved and supported financially by Shiraz University of Medical Sciences, Shiraz, Iran (grant No. 94-7502). The authors express their gratitude to Shiraz University of Medical Sciences as well as all individuals who contributed to the implementation of this study and the interviews.

\section{Conflict of Interest:}

There is no conflict of interest to be declared.

\section{Authors' contributions:}

All authors contributed to this project and article equally. All authors read and approved the final manuscript.

\section{References}

1) Ferdosi M, Farahabadi S, Mofid M, Rejalian F, Haghighat M, Naghdi P. Evaluating the Outsourcing of Nursing Services in Kashani Hospital, Isfahan. Health Inform Manage. 2012; 9(7): 989-96.

2) WHO (World Health Organization). World Health Report 2000. 2000. Geneva. 
3) Barrows D, Macdonald L, Supapol A, Dalton-Jez O, Harvey-Rioux S. Public Private Partnerships In Canadian Healthcare: A Case Study Of The Brampton Civic Hospital. Prepared For The OECD, March 2011.

4) Taylor R, Blair S. Public policy for the private sector; Options for Reform through Public-Private Partnerships: The World Bank's Private Sector and Infrastructure Network; 2002.

5) Mckee M, Edwards N, Atun R. Public Private Partnerships for Hospitals. Bulletin of the World Health Organization. 2006; 84(11): 890-6, PMID: 17143463, PMCID: PMC2627548.

6) Gholamzadeh Nikjo R, Jabbari Bryrami H, Dadgar E. The study of Public-Private Partnership Options in Public Hospitals. National Conference on Privatization in Iran, Tehran: 2012.

7) European Union Commission. Public works contracts, public supply contracts and public service contracts. Available from: http://europa.eu/legislation_summaries/internal_market/businesses/public_procurement/122009_en.htm

8) Gholamzadeh Nikjoo R, Jabbari Beyrami H, Jannati A, Asghari Jaafarabadi M. Prioritizing Public- Private Partnership Models for Public Hospitals of Iran Based on Performance Indicators. Health Promot Perspect. 2012; 2(2): 251-64. doi: 10.5681/hpp.2012.031.

9) Qiao L, Wang SQ, Tiong RLK, Chan TS. Framework for critical success factors of BOT projects in China. The Journal of Project Finance. 2001; 7(1): 53-61. doi: 10.3905/jsf.2001.320244.

10) Jefferies M, Gameson R, Rawlinson S. Critical success factors of the BOOT procurement system: reflection from the Stadium Australia case study. Eng Construct Architect Manag. 2002; 9(4): 352-61, doi: 10.1046/j.1365-232X.2002.00249.x.

11) Li B, Akintoye A, Edwards PJ, Hardcastle C. Critical success factors for PPP/PFI projects in the UK construction industry. Constr Manage Econ. 2005; 23(5): 459-71. doi: 10.1080/01446190500041537.

12) Mobaraki H, Danesh Dehkardi N, Najafi M. Comprehensive plan to reform the system of hospital management. Tehran: Ministry of Health. 2005: 7-10.

13) Shadpour P, Barzegar M, Afzal E. Study on the Impact of Implementing Public-Private Partnership (PPP) at Hasheminejad Kidney Center. Int j hosp res. 2013; 2(4): 195-200.

14) Onwuegbuzie AJ, Collins KM. A typology of mixed methods sampling designs in social science research. Qual Rep. 2007; 12(2): 281-316.

15) Boswell C, Cannon s. Introduction to nursing research. 3 ed: Burlington, MA: Jones \& Bartlett Publishers; 2012.

16) Jalali R. qualitative research sampling. Journal of qualitative Research in Health Sciences. 2013; 1(4): 31020.

17) Forman J, Damschroder L. Qualitave content analysis. Empirical Research for Bioethics: A Primer. Oxford: Elsevier Publishing 2008.

18) Beigzadeh A, Okhovati M, Mehrolhasani MH, Shokoohi M, Bazrafshan A. Challenges of the Bachelor Program of Health Services Management: A Qualitative Study. Journal of Health Administration. 2014; 17(55): 29-42.

19) Holloway I, Wheeler S. Qualitative research in nursing and healthcare. 3rd ed. UK: Wiley- Blackwell; 2010: 297-314.

20) Moazzami A. Requirements and Prerequisites for Partnership with Private Sector in Health Sector. Liman Magazine Consulting Architects \& Engineers. 2015; 5: 74-9. Available from: http://www.liman-co.com.

21) Tabibi SJ, Maleki MR, Nasiripour AA, Barzegar M. Comparative study of public-private partnership in hospitals of Iran and other selected countries. Ind J Fund Appl Life Sci. 2015; 5(2): 1589-97.

22) Grimsey D, Lewis MK. Public Private Partnerships: The Worldwide Revolution in Infrastructure Provision and Project Finance. Cheltenham, UK: Edward Elgar, 2004. doi: 10.4337/9781845423438.

23) Himalika Narangoda B, Khathibi A. Public Private Partnership in Healthcare Industry in Sri Lanka as an Alternative to Privatization. Int J Manag Bus Res. 2014; 4(2): 95-106.

24) Torchia M, Calabrò A, Morner M. Public-private partnerships in the health care sector: A systematic review of the literature. Public Manag Rev. 2015; 17(2): 236-61. doi: 10.1080/14719037.2013.792380.

25) Billé R. Action without Change? On The Use and Usefulness of Pilot Experiments in Environmental Management. S.A.P.I.EN.S [Online] 2010; 3(1): 1-6. Available from: http://sapiens.revues.org/979.

26) Waiter S, Ensor T, Jowett M, Thompson R. Health Economics for Developing Countries, 1st edition London: Macmillan education LTD; 2000. 